\title{
Ontology Modeling for a Drought Management Information System
}

\author{
Nattapong Kaewboonma \\ Information \& Communication Management Program, \\ Khon Kaen University, Thailand \\ kaewboonma@gmail.com \\ Kulthida Tuamsuk (corresponding author) \\ Information \& Communication Management Program, \\ Faculty of Humanities and Social Sciences, Khon Kaen University, Thailand \\ kultua@kku.ac.th \\ Marut Buranarach \\ Language and Semantic Technology (LST) Laboratory, \\ National Electronics and Computer Technology Center (NECTEC), Thailand \\ marut.buranarach@nectec.or.th
}

\begin{abstract}
Thailand suffers from frequent flooding during the monsoon season and droughts in summer. In some places, severe cases of both may even occur. Managing water resources effectively requires a good information system for decision-making. There is currently a lack in knowledge sharing between organizations and researchers responsible. These are the experts in monitoring and controlling the water supply and its conditions. The knowledge owned by these experts are not captured, classified and integrated into an information system for decisionmaking. Ontologies are formal knowledge representation models. Knowledge management and artificial intelligence technology is a basic requirement for developing ontology-based semantic search on the Web. In this paper, we present ontology modeling approach that is based on the experiences of the researchers. The ontology for drought management consists of River Basin Ontology, Statistics Ontology and Task Ontology to facilitate semantic match during search. The hybrid ontology architecture can also be used for drought management
\end{abstract}

\section{INTRODUCTION}

Thailand has an average annual rainfall of over $1,300 \mathrm{~mm}$. and suffers from frequent flood and drought due to the uneven distribution of rainfall. Flood usually occurs during the monsoon season (September-October) when there is intense precipitation. Drought (mainly water shortages for irrigation purposes) occurs in summer (April) or when rainfall is delayed in the early part of the rainy season (June). Some areas experience both flood and drought in a single year from either the temporal and spatial uncertainties in the monthly rainfall or the poor management of the conveyance infrastructure. The common practice in Thailand is to manage the risks after considering which areas are likely to be vulnerable to either flood or 
drought. Failure to manage such risks can lead to adverse results such as importing water from other basins to boost water supply, which in turn multiplies the risk of flooding in the downstream area. This approach is not desirable because the country would have to spend on additional investments in importing water and on flood protection measures. Therefore, managing flood and drought risks is a new challenge for Thailand and is becoming an increasingly important consideration because of global warming (Chitradon, Boonya-aroonnet \&Thanapakpawin, 2009).

Managing water resources effectively requires a good information system for decisionmaking. The Thai Meteorological Department, the Royal Irrigation Department, the Department of Water Resources, the Department of Groundwater Resources, and the Electricity Generating Authority of Thailand are all government bodies responsible for providing water resource information.

However, there is still a lack of knowledge sharing between these organizations and researchers, who are the experts in monitoring and controlling the water supply and ensuring its quality. The knowledge owned by these experts are not captured, classified or integrated into an information system for decision-making. In this sense, water resource management in Thailand becomes a complex problem. Optimal management requires an integrated and interdisciplinary approach, which can be realized with an intelligent tool built upon the concepts and methods of human reasoning (Comas \& Llorens, 2002). The diversity and complexity of conceptual terminology in the industry and the lack of proper document management have made it difficult to systematically arrange, preserve and share the existing knowledge required by the engineers. Connections between model developers and application users are needed. The application of knowledge management (KM) is an answer to assist engineers in the search for knowledge efficiently and effectively. The field of KM techniques can simulate human proficiency in narrowly defined domain during the problem solving stage by integrating descriptive, procedural and reasoning knowledge (Chau, 2007).

Ontology has been widely accepted as a useful method to arrive at a common ground for communication. It also supports a diversity of activities in KM, like the storage, recovery, sharing and distribution of knowledge (Gruber, 1995; Neches, Fikes, Finin, Gruber, Patil, Senator \& Swartout, 1991). More importantly, ontology makes communication and the reuse of knowledge among different entities to share at the same domain possible (Pundt \& Bishr, 2002).

The ontology modeling approach based on the experiences of the researchers as they developed a drought management ontology for the water resources management system is reported. The Chi River Basin was used as a case study because of the interest of the researchers who are experts in monitoring and controlling the water supply that affects the agriculture and industry of the region.

The design of ontology in this research is unique because it uses a hybrid ontology architecture, which comprises of three types of ontology: River Basin Ontology, Statistics Ontology, and Task Ontology, whereas only a single ontology was used in previous studies.

\section{LITERATURE REVIEW}

Ontology can be defined as an explicit specification of a conceptualization. The term is borrowed from philosophy, where ontology is a systematic account of existence. For AI systems, what "exists" is that which can be represented (Gruber, 1993). There are two important aspects of this definition:

1. Explicit: The meaning of each concept is clearly and uniquely defined. 
2. Formal: The concepts in the ontology are defined in a formal language that is easily understood by machines. Many relationships in ontology can link different concepts together into a big concept network allowing the machine to search through the created knowledge (Antoniou \& Harmelen, 2004).

Ontologies can be classified according to their generality level. Different types of ontologies may be used for different purposes (Mizoguchi \& Vanwelkenhuysen, 1995; Van Heijst, Schreiber \& Wielinga, 1997; Guarino, 1998; Ikeda, Seta, Kakusho \& Mizoguchi, 1998; Lassila \& McGuinness, 2001; Fensel, 2003; Agrawal, 2005). Among others, the following ontology types can be distinguished:

- Terminological ontologies such as lexicons specify the terms that are used to represent knowledge in the domain of discourse. An example of such an ontology in the medical field is the semantic network in the Unified Medical Language System (Lindberg, Humphreys \& McCray, 1993).

- Information ontologies which specify the record structure of databases. Level 1 of the PEN \& PAD model, a framework for modeling medical records of patients, is a typical example of such an ontology in the medical field. At this level, the model provides a framework for recording the basic observations of patients, but it makes no distinction between symptoms, signs, treatments, etc. (Rector, Nowlan, Kay, Goble \& Howkins, 1993).

- Knowledge modeling ontologies specify conceptualizations of a knowledge area. Compared to information ontologies, knowledge modeling ontologies usually have a richer internal structure. Further, these ontologies are often tuned to a particular use of the knowledge that they describe. Knowledge modeling ontologies are of particular interest in the context of knowledge-based system development. The Level 2 description of the PEN $\&$ PAD model is an example of a knowledge modeling ontology in the medical field. At this level, the Level 1 observation is grouped to describe the decision-making process.

- Application ontologies contain all the definitions that are needed to model the knowledge required for a particular application. Typically, application ontologies are a mix of concepts that are taken from domain ontologies and from generic ontologies. Moreover, application ontologies may contain method- and task-specific extensions. Application ontologies are not reusable themselves. They may be obtained by selecting theories from the ontology library, which are then fine-tuned for the particular application. The term application ontology is used in a similar way as in PROTEGE-II (Tu, Eriksson, Gennari, Sharar \& Musen, 1995).

- Domain ontologies are reusable in a given specific domain (medical, pharmaceutical, engineering, law, enterprise, automobile, etc.). These ontologies provide vocabularies about concepts within a domain and their relationships, about the activities taking place in that domain, and about the theories and elementary principles governing the domain. There is a clean boundary between domain and upper-level ontologies. The concepts in domain ontologies are usually specializations of concepts already defined in top-level ontologies, and the same might occur with the relations. For instance, the term City in a domain ontology is a specialization of a more generic concept Location, which is a specialization of the term SpatialPoint that may be defined on the upper-level ontology. Similarly, the relations defined in an upper-level ontology can be specialized to express that a road connects two cities (roadConnectsCities) in a domain ontology (Mizoguchi \& Vanwelkenhuysen, 1995; Van Heijst, Schreiber \& Wielinga, 1997). 
Table 1. Development of ontologies on water resources management domain

\begin{tabular}{|c|c|c|c|}
\hline Researcher & Domain & $\begin{array}{l}\text { Approach/ } \\
\text { Technique/Process }\end{array}$ & Type \\
\hline Chau, 2007 & $\begin{array}{l}\text { Flow and Water } \\
\text { quality }\end{array}$ & $\begin{array}{l}\text { Specification Conceptualization } \\
\text { Formalization and } \\
\text { Implementation }\end{array}$ & $\begin{array}{l}\text { - Information } \\
\text { ontology } \\
\text { - Domain } \\
\text { ontology }\end{array}$ \\
\hline $\begin{array}{l}\text { López-Pellicer, } \\
\text { Vilches-Blázquez, } \\
\text { Nogueras-Iso, } \\
\text { Corcho, Bernabé \& } \\
\text { Rodriguez, } 2007\end{array}$ & Hydrographical & $\begin{array}{l}\text { Hybrid approach (top-down } \\
\text { and bottom-up techniques) }\end{array}$ & $\begin{array}{l}\text { - Application } \\
\text { ontology } \\
\text { - Domain } \\
\text { ontology }\end{array}$ \\
\hline $\begin{array}{l}\text { Ceccaroni, Cortés, } \\
\text { \&Sànchez-Marrè, } \\
2004\end{array}$ & Wastewater & $\begin{array}{l}\text { Integration of an ontology with } \\
\text { case-based reasoning and rule- } \\
\text { based reasoning }\end{array}$ & $\begin{array}{l}\text { - Domain } \\
\text { ontology }\end{array}$ \\
\hline $\begin{array}{l}\text { Cabezut-Boo, \& } \\
\text { Sánchez-Aguilar, } \\
1999\end{array}$ & Wastewater & $\begin{array}{l}\text { Integration of an ontology with } \\
\text { rule-based reasoning }\end{array}$ & $\begin{array}{l}\text { - Domain } \\
\text { ontology }\end{array}$ \\
\hline
\end{tabular}

- Generic ontologies are similar to domain ontologies, but the concepts that they define are considered to be generic across many fields. Typically, generic ontologies define concepts like state, event, process, action, and component. The concepts in domain ontologies are often defined as specializations of concepts in generic ontologies. Certainly the borderline between generic ontologies and domain ontologies is vague, but the distinction is intuitively meaningful and is useful for building libraries.

- Representation ontologies explicate the conceptualizations that underlie knowledge representation formalisms (Davis, Shrobe \& Szolovits, 1993). They are intended to be neutral with respect to world entities (Guarino \& Boldrin, 1993). That is, they provide a representational framework without making claims about the world. Domain ontologies and generic ontologies are described using the primitives provided by representation ontologies. An example in this category is the Frame Ontology, which is used in Ontolingua (Gruber, 1993).

- Task, method, or problem-solving ontologies refer to the subject of problem solving. Task ontologies are a system of vocabulary for describing problem solving structure of all the existing tasks independent of domain. It does not cover the control structure but does cover components or primitives of unit inferences taking place during task performance. Task knowledge in turn specifies domain knowledge by giving roles to each object and relation between them. Examples in task scheduling include schedule recipient/schedule resource/goal/constraint/availability/load/select/ assign/classify/remove/relax/add (Mizoguchi, Tijerino \& Ikeda, 1992; Mizoguchi \& Vanwelkenhuysen, 1995; Hori \& Nakamura, 1994; Wielinga \& Schreiber, 1993). 
There have been several attempts to develop water resource management ontologies (see Table1). Chau (2007) developed an information ontology which represented a metamodel comprising generic concepts and attributes which are represented by Dublin Core elements. On the other hand, key concepts, attributes, instances, and relations of flow and water quality modeling are located in the domain ontology (Chau, 2007).

Ceccaroni, Cortés and Sànchez-Marrè (2004) developed an Ontology-based Environmental decision-support system to the domain of wastewater, and applied the ontology with case-based reasoning and rule-based reasoning. In addition, Cabezut-Boo \& Sánchez-Aguilar (1999) developed a library of cases and the domain ontology of wastewater treatment plants.

López-Pellicer, Vilches-Blázquez, Nogueras-Iso, Corcho, Bernabé and Rodriguez (2007) used a hybrid approach for domain ontology development, which merges top-down and bottom-up techniques. In the top-down approach, the concepts in the ontology are derived from an analysis and study of relevant information sources about the domain. In the bottomup approach the concepts in the ontology are the result of applying formal methods on an analysis of the data instances on the repositories and comparison of ontologies to find a consensus between two approaches.

It was found that, in the earlier studies on the development of ontologies, there were specific ontologies namely domain ontology, information ontology and application ontology. These ontologies can explain generic concepts and relations of water resource management domain. We observed that the sources used and the methodology/approaches with respect to the nature and granularity of the components that are considered potentially reusable are very different.

However, an ontology should be designed and developed in relation to the application and context. For example, a domain ontology is used to collect all knowledge about water resource management, as well as represent all terms in noun form (such as basic knowledge of river basin, sub-river basin, and land use) in order to facilitate future reuse of the ontology.

Moreover, water resource management requires a great deal of statistics to monitor the current situation, for example volume of water from the dam, reservoir and climate data. It is a benefit to information systems developers if the information ontology is specifically designed and developed to collect all statistics relating to water resource management. The developers can easily map existing database with the ontology and verify that the ontology has a better coverage of the domain.

\section{THE APPROACH}

In this section, the ontology design and methodology for data integration of government repositories are described in two steps: 1) the ontology modeling approach, and 2) the hybrid ontology architecture. The ontology contains information on weather, water demand, water supply, land use, water quality and water quantity.

In the first step, the knowledge acquisition approach by Liou (1990) was adopted for acquiring knowledge from the domain experts. The study involved four steps:

1. Document analysis to identify the concept and domain knowledge.

2. Drafting the classification following the concept of categorization, considering both common and different attributes by evaluating the data types and the characteristics of the data using a hierarchical clustering of water resource management terms.

3. Interviews with ten experts who are researchers in the areas of environmental engineering, water resource engineering, and Geographic Information Systems in the Chi River Basin 
from four universities located on CRB in the northeast of Thailand. Also interviews with seven government officers who were working with water management in the CRB from the Royal Irrigation Department, Land Development Department, Department of Water Resources, Department of Disaster Prevention and Mitigation, Provincial Administrative Organization, Department of Groundwater Resources, Regional Centre for GeoInformatics and Space Technology, Northeast Thailand, and Regional Environmental Office.

4. Summarizing the knowledge domain and reconfirming the results with the experts. See the ontology modeling approach in Figure 1.

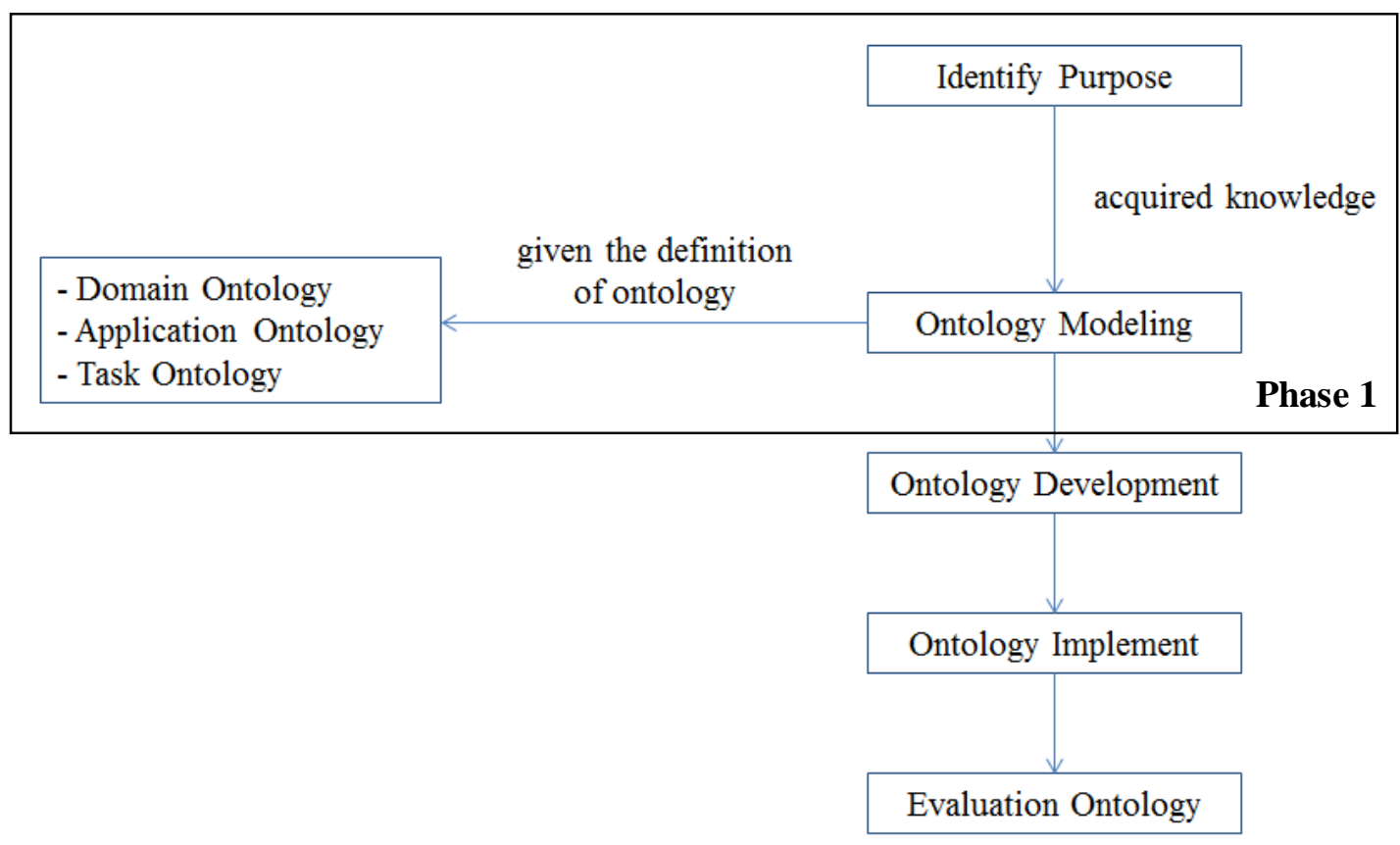

Figure 1. Ontology modeling process

Concerning the difference of geography and climate in each region of Thailand, the area-based problem solving solution should be applied. Thus, it needs the specific information of each area so that the collection of information is enough for further analysis and processing.

Many government agencies take crucial roles in solving the issue of water resources management. The roles involves incident prevention and preparation, aids during incidents, and recovery. By analyzing all information, it was found that there are three types of information needed to manage flooding, drought and wastewater. These three types are: 1) general information about river basin; 2) statistics collected by government agencies; and 3) disaster management processes.

Given the definition of ontology, in this section, the type of ontology used is decided by the modeling aim. For example, if the ontology is intended to provide the record structure of databases for application fields, it is best to choose the information ontology. If the ontology will link verbs with the management process or problem solving structure concepts, possibly a task ontology is needed. 


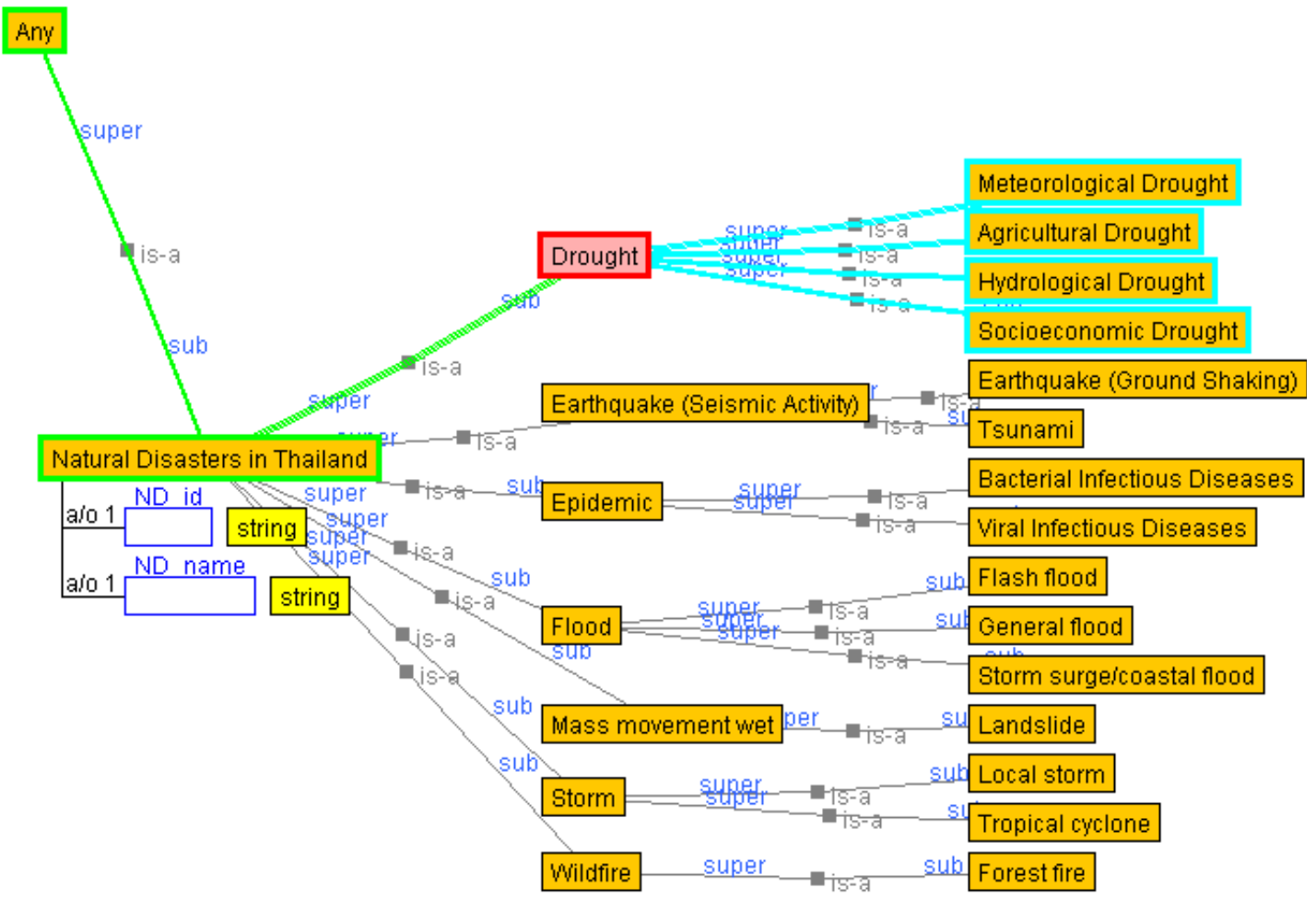

Figure 2. Example of class and class hierarchy of River Basin Ontology

\section{RESEARCH RESULTS}

Based on the ontology modeling process, the ontology has been divided into three groups, namely, the River Basin Ontology, Statistics Ontology and Task Ontology:

1. The River Basin Domain Ontology represents the key concepts of the domain.

2. The Statistics Ontology shows a drought statistic and attributes of weather, water demand, water supply, water quality, water quantity, land use and government provincial resources support. It was observed that there existed various units of data, namely, functional relations, structural relations, and so on.

3. The Task Ontology illustrates the top-level concepts and relationships of a drought cycle management process.

\section{The River Basin Ontology}

The River Basin Ontology was developed by following the top-down approach for the analysis, and study of relevant information sources in the water resources management domain and the emphasis on the ontology components (concepts, attributes, relation and instances). The River Basin Ontology represents the key concepts of the domain (River Basin and Sub-River Basin, Dam and Reservoir, Geographic Information Systems, Land Use, Natural Disasters, etc.) as shown in Figure 2. The terms of the concepts are given in both Thai and English, such as: River Basin Name, Sub-River Basin Name and Land Use Classification.

The River Basin Ontology was defined together with corresponding vocabularies. In order to have grounding for all the data that were needed for drought management, a controlled vocabulary was developed together with relations between terms. 


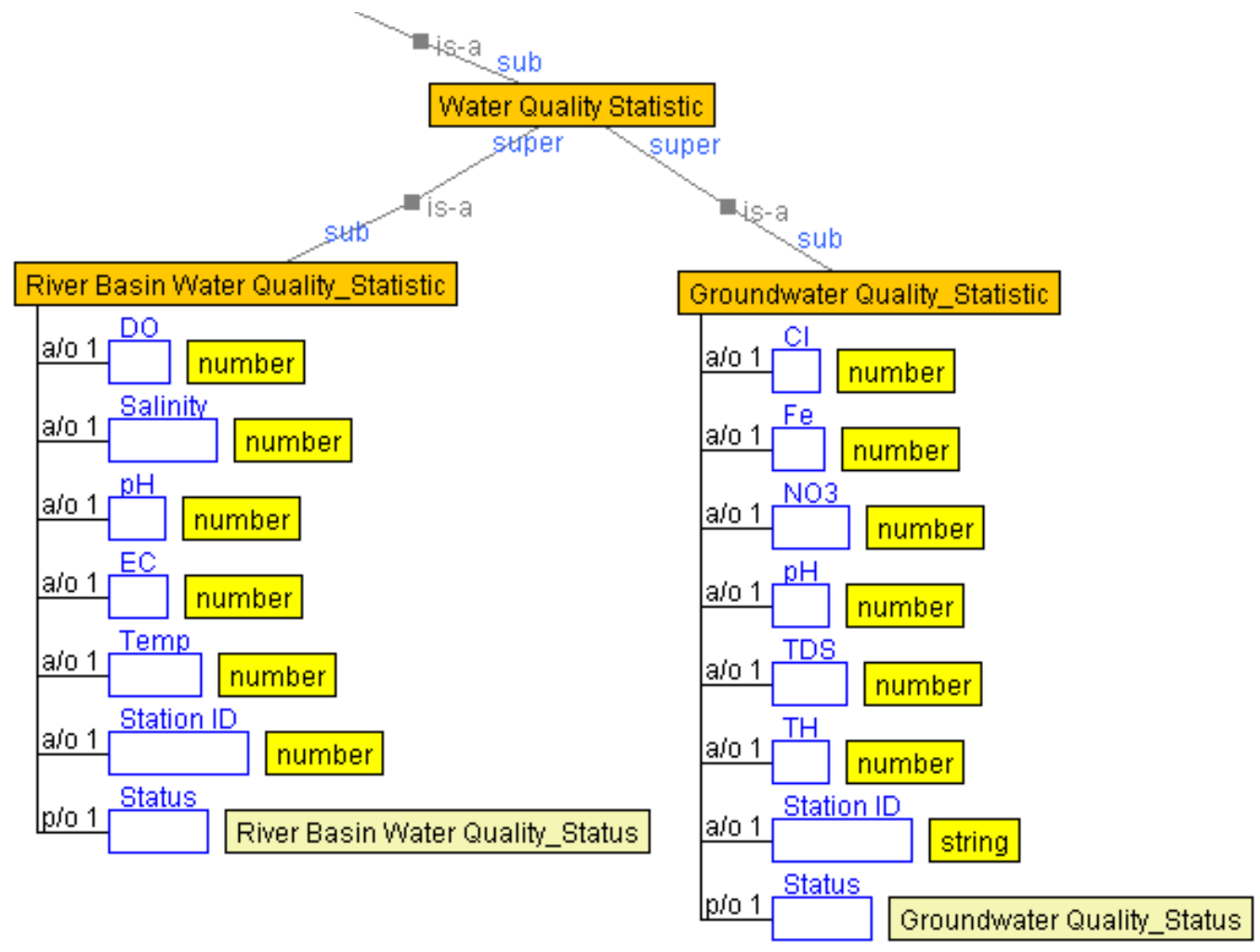

Figure 3. Example of class and class hierarchy of Statistics Ontology

\section{The Statistics Ontology}

The development of the Statistics Ontology followed a bottom-up approach to output a hierarchy of concepts from the feature instances contained in the repositories of government bodies used as data sources. The Statistics Ontology is used to describe the datasets (e.g., Weather, Water Demand, Water Supply, Water Quality, Water Quantity, Land Use and Government Provincial Resources Support) that are needed for drought management. They are independent from the domain of drought management, because all these datasets can be used for other domains. With the Statistics Ontology, several datasets can be combined (e.g., Water Quantity information is synthesized from River Basin Statistics, Reservoir Statistics, Dam Statistics, and Groundwater Statistics). In drought management, the data were numerous, not only from the existing databases but also from the Government Provincial Resources Support (e.g., Pre-Drought Statistics, During-Drought Statistics, and After-Drought Statistics) that need to be processed and combined as shown in Figure 3.

\section{The Task Ontology}

The Task Ontology describes the dataset of task operations by the Government Provincial Resource Support. The set of tasks data includes three processes of drought management: PreDrought Management, During-Drought Management and After-Drought Management. Verbs are defined in the Task Ontology. is- $a$ relations and part-of relations were applied to define a class hierarchy. The class hierarchy of Government Provincial Resource Support is explained. The subclass of Pre-Drought Management (e.g., water quality alerts) will link to Statistics Ontology (Figure 4) to retrieve the dataset of Pre-Drought Statistics. 


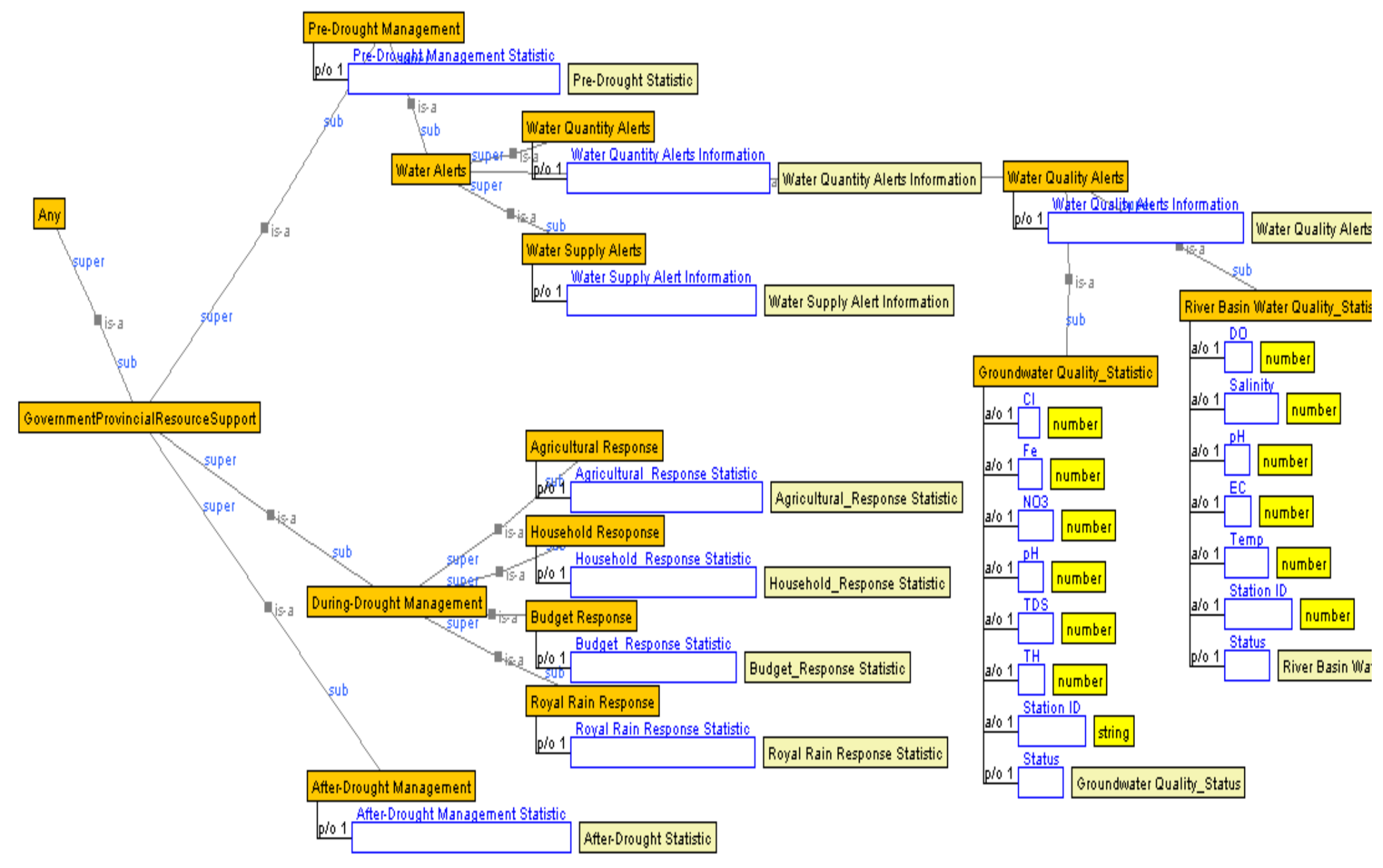

Figure 4. Examples of classes and class hierarchy of the Task Ontology 


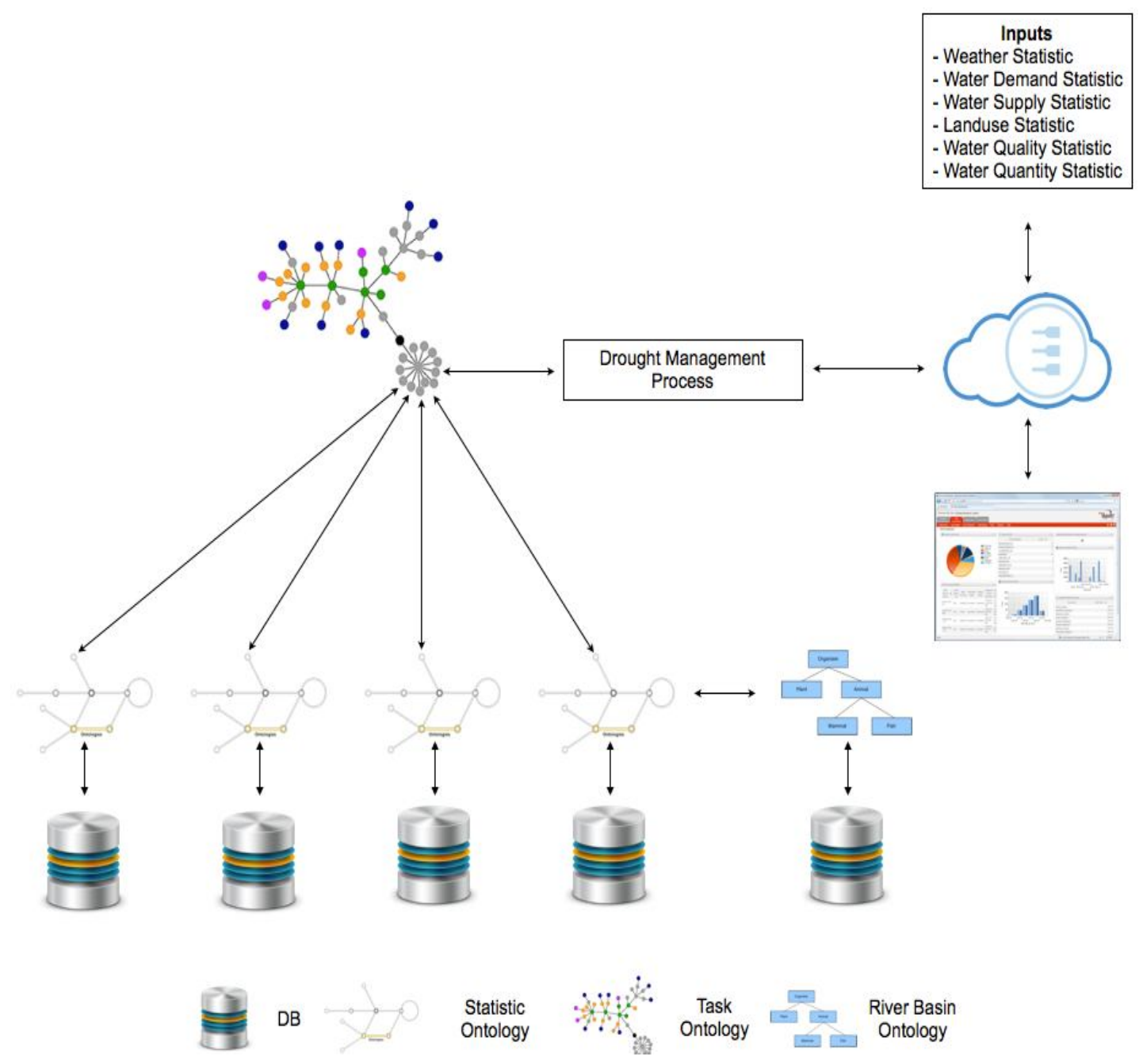

Figure 5. Hybrid ontology architecture

\section{HYBRID ONTOLOGY ARCHITECTURE}

There are three different designs for using ontologies; a global (single) ontology, peer-to-peer (multiple) ontologies, and hybrid ontologies (Visser \& Stuckenshmidt, 2002; Wache et al., 2001). The hybrid ontology architecture was chosen for drought management information system (Figure 5). Drought management is so complex that the use of only one global ontology is believed to be insufficient to model the domain. Although peer-to-peer ontologies can certainly describe the domain, they will result in relatively main ontologies. Since many datasets need to be combined, with participation from many organizations, therefore the ontologies for drought management have to comprise the Statistics Ontology, Task Ontology, and River Basin Ontology.

Generally speaking, Statistics Ontology serves as the glue integrating different datasets. It helps drought management to discover and combine datasets. Statistics Ontology consists of water statistics of drought management from agencies participating in drought management (the Royal Irrigation Department, Land Development Department, Department of Water Resources, Department of Disaster Prevention and Mitigation, Electricity Generating Authority of Thailand, Provincial Administrative Organization, Department of Groundwater 
Resources, Thai Meteorological Department, Regional Centre for Geo-Informatics and Space Technology, Northeast Thailand, and Regional Environmental Office).

\section{SUMMARY AND FUTURE WORK}

This paper presented an ontology modeling approach in order to develop an ontological knowledge base for a drought management information system, focusing on the ontology design process. In the ontology modeling step, the ontology was divided into three types, namely, the River Basin Ontology, Statistics Ontology and Task Ontology. The River Basin Ontology was developed following the top-down approach focusing on the dataset from the domain of water information. The Statistics Ontology was developed following a bottom-up approach focusing on statistical data of drought management. The Task Ontology was developed by using the is-a relation and part-of relation to define the class hierarchy focusing on the dataset of operating tasks of drought management. These three types of ontologies were linked and mapped onto a database.

In the future, the ontology will be constructed using the Hozo Ontology Editor (Kozaki, Kitamura, Ikeda \& Mizoguchi, 2002). The ontology will be embedded in an Ontology-based Application Management (OAM) framework (Buranarach, Thein \& Supnithi, 2012). It is an integrated platform that supports both RDF data publishing from databases and processing of the published data in an ontology-based application, i.e. a semantic search and recommender system application to provide an ontology-based semantic search system and web-based knowledge visualization system. This will enable the information retrieval functions of the system to operate automatically, efficiently and accurately. The number of searches and the time needed to search can also be reduced.

\section{ACKNOWLEDGEMENTS}

The authors express our gratitude and appreciation to Associate Prof. Dr. Asanee Kawtrakul and Dr. Thepchai Supnithi from the National Electronics and Computer Technology Center (NECTEC), Thailand for their kind suggestions.

\section{REFERENCES}

Agarwal, P. (2005). Ontological considerations in GIScience. International Journal of Geographical Information Science, 19(5), 501-536.

Antoniou, G., \& van Harmelen, F. (2004). A semantic web primer. Cambridge, MA: MIT Press.

Buranarach, M., Thein, Y.M., \& Supnithi, T. (2012). A community-driven approach to development of an ontology-based application management framework. In Proceedings of the 2nd Joint International Semantic Technology Conference (JIST2012) (pp. 306312). Berlin: Springer, LNCS, Springer, December 2012.

Cabezut-Boo, O., \& Sánchez-Aguilar, A. (1999). Towards an ontology of wastewater treatment plants: The identification phase. Binding Environmental Sciences and Artificial Intelligence, 14(5), 401-408.

Ceccaroni, L., Cortés, U., \& Sànchez-Marrè, M. (2004). OntoWEDSS: Augmenting environmental decision-support systems with ontologies. Environmental Sciences and Artificial Intelligence, 19(9), 785-797.

Chau, K. W. (2007). An ontology-based knowledge management system for flow and water quality modeling. Advances in Engineering Software, 38(3), 172-181. 
Chitradon, R., Boonya-aroonnet, S., \&Thanapakpawin, P. (2009). Risk management of water resources in Thailand in the face of climate change. Sasin Journal of Management, 15(1), 64-73.

Comas, J., \& Llorens, E. (2002). The STREAMES project: Linking heuristic and empirical knowledge into an expert system to assess stream managers. Retrieved October 13, 2014, from http://www.iemss.org/iemss2002/proceedings/pdf/ volume\%20tre/286_comas.pdf

Davis, R ., Shrobe, H., \& Szolovits, P. (1993). What is a knowledge representation? AI Magazine, 14(1), 17 - 33 .

Fensel, D. (2001). Ontologies: Silver bullet for knowledge management and electronic commerce. Berlin: Springer-Verlag.

Gruber, T. (1993). A translation approach to portable ontology specifications. Knowledge Acquisition, 5(2), 199-220.

Gruber, T.H. (1995). Toward principles for the design of ontologies used for knowledge sharing. International Journal of Human-Computer Studies, 43(5/6), 907-928.

Guarino, N. (Ed.). (1998). Formal ontology in information systems: Proceedings of the first international conference (FOIS'98), June 6-8, Trento, Italy. Amsterdam: IOS press.

Guarino, N ., \& Boldrin, L . (1993). Ontological requirements for knowledge sharing. Paper presented at the IJCAI Workshop for Knowledge Sharing and Information Interchange, Chambery, France.

Hori, M., \& Nakamura, Y. (1994). Reformulation of problem-solving knowledge via a taskgeneral level. In Proceedings of the 3rd Japanese Knowledge Acquisition for Knowledge-Based Systems Workshop (JKAW'94) (pp. 1-15).

Ikeda, M., Seta, K., Kakusho, O., \& Mizoguchi, R. (1998). Task ontology: Ontology for building conceptual problem solving models. In 13th European Conference on Artificial Intelligence (pp. 126-133).

Kozaki, K., Kitamura, Y., Ikeda, M., \& Mizoguchi, R. (2002). Hozo: An environment for building/using ontologies based on a fundamental consideration of "Role" and "Relationship". In Proceedings of the 13th International Conference Knowledge Engineering and Knowledge Management (EKAW2002) (pp. 213-218).

Lindberg, D.A.B., Humphreys, B. L. \& McCray, A. T. (1993). The unified medical language system. Methods of Information in Medicine, 32, 281-291.

Liou. Y.I. (1990). Knowledge acquisition: Issues, techniques, and methodology. In Proceedings of the 1990 ACM SIGBDP Conference on Trends and Directions in Expert Systems (SIGBDP'90) (pp. 212-236). New York: ACM.

López-Pellicer, F.J.,Vilches-Blázquez, L.M., Nogueras-Iso, J.,Corcho, Ó., Bernabé, M.A., \& Rodriguez, A.F. (2008). Using a hybrid approach for the development of an ontology in the hydrographical domain. In 2nd Workshop on Ontologies for Urban Development: Conceptual Models for Practitioner, 17-18 October, 2007, Castello del Valentino, Turin, Italy (pp. 1-15). Retrieved October 13, 2014, from http://oa.upm.es/5148/1/Using_a_hybrid_approach_for_the_development_of_an_ontol ogy_in_the_hydrographical_domain.pdf

Mizoguchi, R., \& Vanwelkenhuysen, J. (1995). Task ontology for reuse of problem solving knowledge. In N.J.I. Mars (Ed.), Towards very large knowledge bases: Knowledge building \& knowledge sharing (pp. 46-59). Amsterdam: IOS Press. 
Mizoguchi, R., Tijerino, Y., \& Ikeda, M. (1992). Task ontology and its use in a task analysis interview systems: Two level mediating representation in MULTIS. In Proceedings of the Second Japanese Knowledge Acquisition for Knowledge-Based Systems Workshop (JKAW'92) (pp. 185-198).

Neches, R., Fikes, R., Finin, T., Gruber, T., Patil, R., Senator, T., \& Swartout, W.R. (1991). Enabling technology for knowledge sharing. AI Magazine, 12(3), 36-56.

Pundt, H., \& Bishr, Y. (2002). Domain ontologies for data sharing: An example from environmental monitoring using field GIS. Computer \& Geosciences, 28(1), 95-102.

Rector, A.L., Nowlan, W.A., Kay, S., Goble, C.A., \& Howkins, T.J. (1993). A framework for modelling the electronic medical record. Methods of Information in Medicine, 32, 109119.

Tu, S.W., Eriksson, H., Gennari, J.H., Shahar, Y., \& Musen, M.A. (1995). Ontology-based configuration of problem-solving methods and generation of knowledge acquisition tools: the application of PROTEGE'-II to protocol-based decision support. Artificial Intelligence in Medicine, 7, 257-289.

Van Heijst, G, Schreiber, A.T., \& Wielinga, B.J. (1997). Using explicit ontologies in KBS development. International Journal of Human-Computer Studies, 45, 183-292.

Visser U., \& Stuckenshmidt, H. (2002). Interoperability in GIS-enabling technologies. In Proceedings of the 5th AGILE Conference on Geographic Information Science, Palma de Mallorca, Spain (p. 291-297).

Wache, H., Vgele, T., Visser, U., Stuckenschmidt, H., Schuster, G., Neumann, H., \& Hbner, S. (2001) Ontology-based integration of information survey of existing approaches. In IJCAI-01 Workshop: Ontologies and Information Sharing, Seattle, Washington (pp. 108-117).

Wielinga, B.J., \& Schreiber, A.T. (1993). Reusable and sharable knowledge bases: A European perspective. In Proceedings of the First International Conference on Building and Sharing of Very Large-Scaled Knowledge Bases (pp. 103-115). Tokyo: Japan Information Processing Development Center. 